\title{
Accountability and the Regulation of Legitimacy: Biodiversity Conservation and Energy Extraction in the American West
}

\author{
Steven Wolf
}

\begin{abstract}
Energy extraction in the western United States poses existential risks to sage-grouse, a charismatic ground-nesting bird. Study of how this concern is integrated into the governance of the sector can inform a broader analysis of sustainability transitions. I introduce a model of coevolution of standards of legitimacy and material practices that highlights how emergence of new accountability 'tests' can potentially drive socioecological transformation. This evolutionary model emphasises accountability and legitimacy as mechanisms of selection (demographic/ behavioural change). Because accountability mechanisms and selection pressures do not exist to transform the Colorado energy sector in a manner that benefits sage-grouse, the assessment reveals that there is no sustainability transition underway. As we focus on the broader analytical and practical challenges presented by sustainability transitions, attention to accountability, legitimacy, and selection mechanisms will be essential.
\end{abstract}

Keywords Sustainable transitions $\bullet$ Accountability $\bullet$ Legitimacy $\bullet$ Biodiversity conservation $\bullet$ Environmental governance

S. Wolf $(\bowtie)$

Department of Natural Resources, Cornell University, Ithaca, NY, USA

e-mail: saw44@cornell.edu

(C) The Author(s) 2020

S. Sareen (ed.), Enabling Sustainable Energy Transitions, https://doi.org/10.1007/978-3-030-26891-6_8 


\subsection{Energy Production and Loss of Biodiversity}

The sage-grouse (Centrocercus urophasianus) is a ground-nesting bird dependent on sagebrush steppe habitat in 11 western states in the United States. The population is in marked decline, with the current range of the species reduced to $56 \%$ its historic distribution (Schroeder et al. 2004). Following formal petitions, US Fish and Wildlife Service concluded an assessment in 2010 (USFWS 2010) to determine if the sage-grouse should be protected under the Endangered Species Act (ESA). In 2010, the federal government determined that protections were warranted based on population estimates and ecological modelling, but that it was not practical to implement protections under the law due to competing demands on the agency. The federal government invited the relevant states to develop conservation plans that would protect the habitat (and ostensibly the population) of sage-grouse. Inducing the creation of these conservation plans can be understood as a means of fulfilling obligations that flow from the Endangered Species Act.

In Colorado, oil and gas development is the leading cause of sagegrouse habitat degradation (Copeland et al. 2009). A leading environmental non-governmental organisation (NGO), Environmental Defense Fund (EDF), organised relevant stakeholders to develop the Colorado Habitat Exchange, a compensatory mitigation programme through which the oil and gas industry could purchase habitat credits to offset habitat degradation associated with their operations. The credits would be supplied by farmers and ranchers who commit to conservation or restoration of land, thereby producing positive gains in habitat. In this way, energy development could be rendered compatible with a commitment to no-net loss of sage-grouse habitat.

In terms of socioecological interplay and feedbacks, energy demand/ supply causes land use disturbance, resulting in sage-grouse population declines and awareness of risks of ecological disturbance. This has the potential to drive social regulation (i.e., the introduction of accountability mechanisms that encourage firms to avoid destroying valuable habitat and to offset habitat loss when avoidance is not practical), which can, in turn, change land use patterns to stabilise populations of sage-grouse. As depicted, this dynamic can be understood as a transition from a situation in which the energy industry contributes in a significant way to risk of sage-grouse extinction to a situation in which the energy industry responds 
to social demand for biodiversity protection and contributes positively to sage-grouse conservation success.

While energy transitions are generally understood to involve a shift from fossil fuels to renewable energy supply, it is useful to consider other challenges. Adaptations that address protection of wildlife, water quality, air quality, workers, and communities where extraction and processing occur all represent important challenges to the industry, the economy, and to social capacity for regulation. Studying the integration of biodiversity concerns into energy development can inform understanding of prospects for sustainability, broadly defined. More generally, this work can demonstrate how attention to accountability and legitimacy can support analysis of environmental governance.

\subsection{Legitimation Crisis, Regulation, and Socioenvironmental Change: An Evolutionary Model of Environmental Governance}

The framing of this volume places accountability and legitimation processes at the centre of environmental governance (see Kraft and Wolf 2018). Accountability mechanisms provide assurance against unacceptable behaviour and serve to regulate flows of legitimacy. Legitimacy is understood to be a socially mediated resource that shapes the prospects of actors, rewards and constrains behaviour, and channels socioeconomic development (e.g., industrial organisation) and material practices (e.g., techniques for producing energy). As contributing authors to this volume, we are asked to analyse practices of legitimation that serve to disrupt-as well as conserve-business as usual in order to advance scholarship on sustainability transitions. At the same time, we are encouraged to identify opportunities to challenge and to change practices/relations of accountability and flows of legitimacy in order to advance sustainability transitions.

Habermas' (1975) analysis of the legitimation crisis draws our attention to systemic dimensions of technical and institutional change within imagined sustainability transitions. For Habermas, the crisis is a state in which there are no problem-solving pathways available to incumbent decision makers. The control/regulatory apparatus is perceived as not being capable of repair or renewal. The anticipated outcome is disruptive innovation, qualitative change; a shift to a different state. 'To the extent that (ecological) scarcity is a technical problem, this does not necessarily constitute a 
crisis. The crisis stems from lack of institutional alternatives. What is scarce is coordination capacity. We do not have proven, practical institutional responses to what ails us, or at minimum, the switching costs and the learning challenges make transition frightening' (Wolf and Bonanno 2014: 287). In these terms, a crisis of legitimacy has the potential to catalyse a transition, some forms of which might be called sustainable. ${ }^{1}$ This transition will entail both technical and institutional state variables. We have not advanced very far in some imagined transition towards sustainability (e.g., reduced reliance on fossil fuels and reduced $\mathrm{CO}_{2}$ flux and reductions in economic stratification), and so it is possible to suggest that there is no legitimation crisis. In other words, people do not interpret the situation in terms of institutional failure. Consumer capitalism appears quite sustainable, and core debates are framed in technical (i.e., post-political (Swyngedouw 2009)) terms. Dominant institutions, dominant actors, and dominant material practices are able to reproduce their legitimacy despite social and ecological contradictions (Piketty 2013; Rockström et al. 2009). For this reason, this book is focused on questions about how this legitimacy is maintained and how new accountability practices might alter flows of legitimacy and advance a sustainability transition.

Science and technology studies has developed the concept of sociotechnical systems, highlighting the mutual embeddedness of social processes and technology. This integrated perspective is rather central to the sustainability transitions literature. In trying to make sense of sociotechnical change and processes of regulation, I identify flows of legitimacy and accountability 'tests' as essential considerations (see top right in Fig. 8.1). Such tests can take the form of laws, administrative rules, professional best practices, technical standards, cultural conventions, investment and consumption behaviours, and other social processes that structure discrimination routines (i.e., processes of selection within an ecological model). Processes of selection, or regulation, are central to an analysis of mechanisms that might produce a sociotechnical transition or rapid 'flip' (i.e., state change) into something we might identify as sustainability. They are also central to the analysis of how sustainability imperatives are blunted and co-opted. Blühdorn (2007) has emphasised the need to analyse how we 'sustain the unsustainable'. The reproduction of selection mechanisms/environments - that is, standards of legitimacy and mechanisms of

\footnotetext{
${ }^{1}$ Authoritarianism is a possible outcome, and the relationship between authoritarianism and sustainability requires reflection.
} 


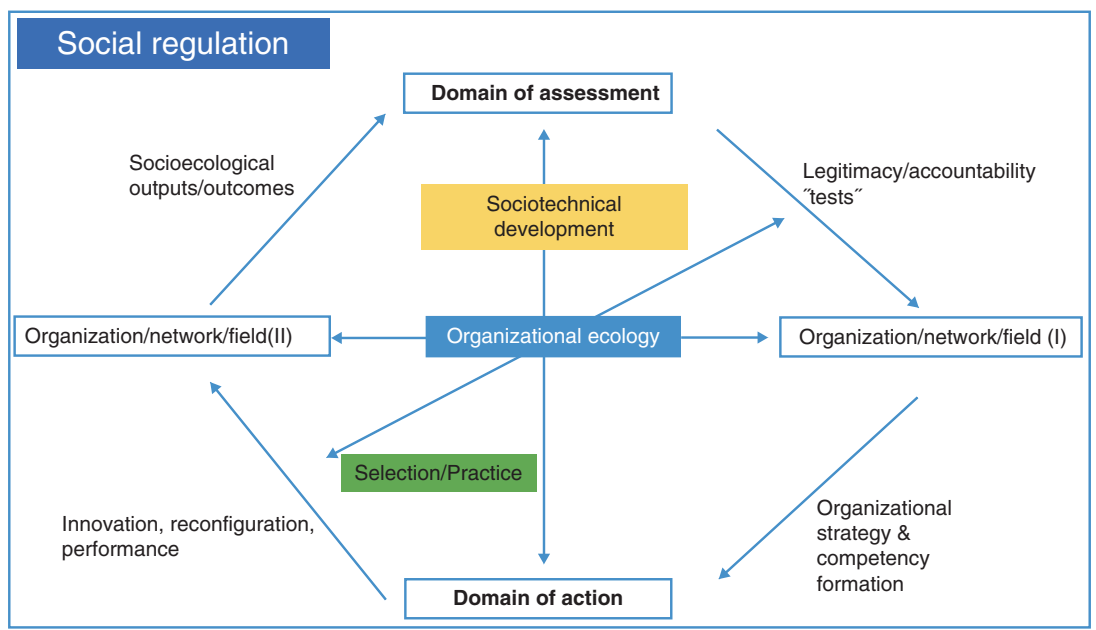

Fig. 8.1 Co-evolution of nature and society mediated by accountability mechanisms and legitimacy tests

accountability - that fail to change the distribution of relevant behaviours and outputs are a central mechanism for path dependence in socioecological systems.

Selection is the process that drives demographic change and demographic stability (i.e., organisational ecology). Here, we can imagine a population of oil and gas firms with variable capacity to respond to new regulations, new eco-audits, or new consumer sensibilities (Wolf and Primmer 2006). In addition to demographic change, selection can alter the distribution of behaviours. Firms adapt more frequently than they disappear. We can imagine the costs of offsetting the degradation of sagegrouse habitat as driving some firms out of business (i.e., churn in the population), and we can imagine such costs as shifting firms' drilling operations to geographic zones outside of prime sage-grouse habitat (an adaptation of technical practices and outputs).

The co-evolutionary model sketched in Fig. 8.1 can help us make sense of incremental processes of socioecological change (adaptation) as well as rapid flips (punctuated equilibrium). Regardless of the pace of change, the analysis presented here emphasises linkages between socially mediated assessments, economic and technical development, and socioecological change (see Norgaard 1994). 
As represented in the model, standards of assessment emerge from culture, politics, and scientific interpretations of socioecological status and trajectory (e.g., changes in biodiversity and the stakes attached to it). Accountability represents a series of relational ties that position some actors to make judgements of others and impose sanctions when appropriate (Bovens 2007). Judgements are based on assessments of how well a given practice or organisation conforms to norms that derive from deep structures of society (i.e., institutions such as family, community, market, state, etc.) (Kraft and Wolf 2018). Sanctions-penalties, taxes, withdrawal of subsidies, consumer boycott, investor flight-hinder performance and reduce competitiveness, by definition, and in this sense, they are an element of selection processes (i.e., organisational ecology). At the same time, shifting standards of accountability and shifts in how legitimacy is produced/accessed gives rise to new organisational strategies and new competencies tied to emerging competitive strategies (Wolf and Primmer 2006). Out of this adaptation dynamic, we observe innovation and reconfiguration of material practices.

Changes in the institutional environment and the competitive landscape also give rise to gestures or performances that communicate engagement with norms, but amount to little material change that can be linked back in any direct way to the new accountability tests mentioned earlier. ${ }^{2}$ Note that these performances-for example, ways of talking about sustainability concerns - can be an element of a new competitive landscape, and in this sense, they are not empty. This dynamic of adaptation-substantive and gestural-produces a newly configured population (i.e., organisation/network/field II), which is characterised by a different distribution of behaviours as well as the introduction of new material practices. These developments constitute socioecological change, and outcomes include changes in ecology and distributional shifts in the wellbeing of people and ecosystems. These outcomes give rise to new ecological risks and opportunities and new social values and politics. In this shifting cognitive and sociomaterial landscape, the stage is set for a new round of assessments and evaluations that constitute accountability practices and structure flows of legitimacy.

\footnotetext{
${ }^{2}$ In addition to disappearing from the population and adaptation, actors also have the potential to shape the selection environment. Lobbying, constructing political coalitions, public relations, and efforts to reshape culture are active strategies relevant for understanding the co-evolution of sociotechnical systems.
} 


\subsection{Accountability Tests and Legitimacy Flows of the Colorado Sage-Grouse Habitat Exchange}

Accountability relations are socially mediated assessments that structure flows of legitimacy and channel sociotechnical development. In reflecting on how declining populations of sage-grouse might give rise to changes in the Colorado energy sector, we can identify a set of important actions that allow us to reflect on how accountability relations and practices of legitimation are implicated in processes of social regulation. The analysis presented here is symmetrical. The aim is to highlight the potential for accountability relations to advance a sociotechnical dynamic that supports the sustainability of sage-grouse populations, and to highlight the potential for these same relations to legitimate and reproduce the sociotechnical dynamic responsible for the existing risk of extinction.

\subsubsection{Construction of a Market-based Habitat Exchange}

Applied to oil and gas extraction in Colorado and the fate of the sagegrouse, the construction of the habitat exchange is an important effort to introduce accountability for habitat loss and it is a key site of production of legitimacy for a range of actors. The exchange is promoted as capable of producing no-net loss of sage-grouse habitat. By quantifying the habitat losses associated with specific oil and gas development projects and the habitat gains associated with conservation actions by Colorado landowners interested in selling habitat credits, the exchange is a platform buying and selling sage-grouse habitat offsets. These offsets are a form of compensatory mitigation. As imagined by designers of the exchange, firms seeking drilling permits from the state purchase the appropriate volume of habitat credits through the exchange, and this makes it possible to advance oil and gas production while safeguarding sage-grouse populations. Compensatory mitigation of habitat loss is the final element of the mitigation hierarchy-avoid, minimise, and offset. The design and administration of the exchange emphasises offsetting as a fallback option. Avoiding development projects that degrade habitat and altering projects to minimise disturbance to habitat advance conservation directly, while offsetting can be understood as providing a more diffuse benefit to sage-grouse.

The Colorado Exchange was created by the Environmental Defense Fund (EDF), a New York-based NGO. EDF partnered with the Colorado 
Cattlemen's Association (representing landowners positioned to sell credits to oil and gas firms) and co-solicited relevant Colorado state agencies, and firms in the energy industry to participate in the creation and governance of the exchange (Large and Wolf 2018). The prospect of the sage-grouse gaining protection from the federal Fish and Wildlife Service through the ESA - and the political and economic fallout of regulation under the ESA - is generally understood as motivating this state-level cooperation. As a market-based approach to environmental management, habitat offsetting is linked to experience with the Clean Air Act, stream bank and wetlands mitigation banking, and the Clean Development Mechanism under the Kyoto Protocol. Reliance on market exchange to structure environmental management grants flexibility to individual firms, responds to criticisms of coercive bureaucratic controls, and ostensibly produces conservation at least aggregate cost. These traits lend habitat offsetting a modern and practical sensibility, which resonates positively with a broad range of relevant actors and varied logics of coordination.

Despite the elegance of the concept, after seven years of design and consultation, the exchange has not generated any habitat offsets. To repeat, the exchange has not supported any transactions that advanced conservation. Regardless of the capacity of the exchange to function, however, the concept of the exchange has produced a sustained dialogue among the central public and private sector policy actors in Colorado and nationwide.

Prospects for further development of the exchange were damaged in the summer of 2018 when the oil and gas industry formally announced that they were resigning from the exchange governance board and that they were not willing to play a further role in its development unless the expectations for offsetting were ratcheted downward. This announcement was followed by EDF shifting their personnel away from development of the exchange. The timing of this rupture was tightly linked to an announcement by the US Secretary of Interior ending mandates that supported compensatory mitigation under ESA. This policy decision was explicitly tied to ambitions to promote 'energy independence'. Over the past year, the Trump administration has continued to roll back legal protections for sage-grouse and, more broadly, to weaken ESA (Davenport/ NY Times 2019).

The habitat exchange was created to serve as a primary vehicle for holding the oil and gas industry accountable for sage-grouse habitat degradation, and it is a primary vehicle for demonstrating to federal regulators-and 
a wide variety of other parties - that ESA protections for sage-grouse are not necessary. The exchange continues to be represented as relevant and vibrant ${ }^{3}$ despite the fact that zero offsets have been created under this governance mechanism and the buyer of offsets has publicly announced their unwillingness to participate. Therefore, it seems reasonable to argue that the exchange serves to legitimate business as usual. The exchange functions to sustain the cognitive dissonance-that is, capacity to reconcile contradictions - attached to existing socioecological relations (Walker et al. 2009). The capacity of the exchange to organise and sustain dialogue in the policy field appears to be sufficient to maintain the legitimacy of existing socioecological relations. According to the co-evolutionary model sketched above (Fig. 8.1), there are no accountability tests and no selection pressure to advance structural or technical changes that could be recognised as a sustainability transition. That said, if a significant political bloc were to commit to conservation, and federal and state regulators were to reverse their position and require firms to purchase offsets (Green 2018), the exchange would be a critical element of the infrastructure supporting governance and sage-grouse conservation. In this sense, it is possible to interpret the exchange as all of the following: a failure, a distraction, and an accomplishment.

\subsubsection{Quantification Tools}

The technical core of the Colorado sage-grouse habitat exchange is the Habitat Quantification Tool (HQT) sage-grouse exchange. This habitat suitability model produces an integrated assessment of how site-specific land use/land cover changes affect the productivity of land for sage-grouse feeding, reproduction, nesting and fledging. HQT scores specify the magnitude of the habitat degradation (debits) associated with direct (e.g., oil and gas well pad and road and electricity service to the well) and indirect effects (e.g., spill overs from disturbed sites that degrade surrounding habitat values, measured through a distance-decay function) sage-grouse. The HQT also scores the positive contributions (credits) associated with conservation activities (e.g., ecological restoration, habitat enhancements,

\footnotetext{
${ }^{3}$ See, for instance, https://www.thepwc.org/habitat-exchangeexchange/ and https:// brianallmerradionetwork.wordpress.com/2018/12/21/12-21-18-co-governorhickenlooper-signs-executive-order-furthering-conservation-and-clarifying-mitigation-ofthe-greater-sage-grouse/.
} 
transfer of development rights). This quantification is the basis for asserting equivalencies across sites and projects, and it makes it possible to assign value and to conduct transactions through the exchange.

EDF convened a panel of scientific experts to produce the HQT, and there was an active effort to shield this process from political and economic considerations. The HQT was peer-reviewed by a committee under the auspices of the Ecological Society of America, as well as by a 3rd-party reviewer selected by the oil and gas industry. The process of creating a science-based routine for accounting of habitat values and to assign rights (credits) and responsibilities (debits) are key practices of accountability advanced by the exchange. The elaborate process through which debits and credits are assigned, and the performances of rigour associated with the algorithm, legitimates the exchange. In fact, habitat exchanges were developed in response to perceived shortcomings of existing models of offsetting based on 'conservation banking' (Toombs et al. 2018; Barral 2019). In conservation banking schemes, offsets are typically assigned based on ad hoc negotiations between administrators and buyers and sellers of credits/debits. There is typically no standardised biological modelling, and rights and responsibilities are not specified a priori. Additionally, offsets in habitat banking programmes have largely been financed by institutional investors engaged in a form of speculation, and there have been limited opportunities for local landowners to participate as suppliers of credits. The HQT responds to concerns about transparency, consistency, and access, which bolsters its legitimacy as a conservation mechanism. In terms of accountability, the HQT is a technical standard that quantifies rights and responsibilities. In terms of legitimacy, this standard presents opportunities for efficient assessment of the extent to which an energy project or firm has internalised a commitment to no-net loss of habitat.

In reflecting on the development and the current status of the exchange, it is worthwhile to note that mobilising science and making significant investments in a standardised, transparent, quantitative approach to assigning habitat values have not succeeded in advancing accountability applied to oil and gas firms' degradation of sage-grouse habitat. From a biological perspective, the sage-grouse does not cope well with disturbance, and this is reflected in the debits assigned by the HQT. A firm building a four-acre well pad in sage-grouse habitat can be assigned as much as 800 acres of offsetting responsibility. Since the HQT was unveiled, the oil and gas industry has consistently raised critical questions about the magnitude of the debits assigned to specific projects. The oil and gas industry has stated 
that they were willing to engage in offsetting, but not according to the terms embedded in the HQT. Ecological discipline can be transmitted through metrics, but power lies elsewhere.

\subsection{Advancing a Sustainable Energy Transition THAT SUPPORTS SAGE-GROUSE}

In reflecting on the Colorado Habitat Exchange as a vehicle to address conservation, it is worthwhile to reflect critically on the conflation of habitat conservation and security of the population of sage-grouse. It is quite possible for the population to collapse without a net loss of habitat. Climate change, invasive species, wildfire, and cumulative impacts from home building, road construction, infrastructure, recreation and other human activities, combined with questions about the fungibility of habitats, raise questions about the coherence of this approach to conservation. Bracketing these issues, these concluding remarks focus on exploring the value of a co-evolutionary perspective for institutional analysis and design.

According to the co-evolutionary model presented here, a transition to a state in which energy supply does not undermine the security of the sage-grouse population requires new accountability tests that derive from new conceptions and new practices of legitimacy. These tests must channel selection in a manner that drives change over time in the distribution of relevant land use behaviours. The change in behaviours derives from a shift in the population of actors and the operational procedures, competencies, and strategies of those actors. Under existing political-economic relations, the exchange is not capable of introducing the required discipline and/or rewarding relevant innovations.

Based on this analysis, research and practical interventions should focus on the potential for new politics and new dynamics in civil, market, and cultural domains that are capable of shifting how legitimacy is produced and accessed. With respect to accountability, there is a need to focus on sanctions (i.e., the imposition of costs and risks capable of reorienting behaviour and strategy). At present, the exchange does not work because there are no mechanisms to create demand for offsets through the exchange, premised on the HQT. Oil and gas firms are able to access drilling permits from the state through other, less stringent regulatory 
pathways. ${ }^{4}$ In the absence of leadership by the state - that is, willingness to impose sanctions on oil and gas firms that are heavy enough to change the extent of land use disturbance and sufficient to conserve sufficient and appropriately configured habitats- the exchange cannot function to conserve sage-grouse. Voluntary commitments by firms are insufficient and consumer preferences are not expressed in a manner capable of producing significant changes. Habitat offsetting, and perhaps most analogous market-based conservation strategies, rest on the existence or creation of demand for offsets. This demand rests on the legislative and judicial redefinition of rights and responsibilities. Unless consumers, investors, voters, and regulators hold these expectations and impose these duties, this environmental governance strategy cannot sustain sage-grouse in Colorado and advance a sustainable transition.

\section{REFERENCES}

Barral, S. (2019). Ecological and management dimensions of metric production in conservation banking. Journal of Rural Studies (In review).

Blühdorn, I. (2007). Sustaining the unsustainable: Symbolic politics and the politics of simulation. Environmental Politics, 16, 251-275.

Bovens, M. (2007). Analysing and assessing accountability: A conceptual framework. European Law Journal, 13(4), 447-468.

Copeland, H. E., Doherty, K. E., Naugle, D. E., Pocewicz, A., \& Kiesecker, J. M. (2009). Mapping oil and gas development potential in the US Intermountain West and estimating impacts to species. PloS one, 4(10), e7400.

Davenport/NY Times. (2019, March 15). Trump administration loosens sage grouse protections, benefiting oil companies. NY Times.

Green, M. (2018, July 27). The Hill. Retrieved May 2019, from https://thehill. $\mathrm{com} /$ policy/energy-environment/399262-administration-ending-rule-thatmade-industry-pay-for-damages-to

Habermas, J. (1975). Legitimation crisis. Boston: Beacon Press.

Kraft, B., \& Wolf, S. (2018). Through the lens of accountability: Analyzing legitimacy in environmental governance. Organization \& Environment, 31, 70-92. https://doi.org/10.1177/1086026616680682

Large, D., \& Wolf, S. (2018). How the endangered state acts: Reverse regulatory threat and market-based conservation policy (In preparation).

${ }^{4}$ Permits are awarded by the state through a process that involves attention to avoidance, minimisation and offsetting. Champions of the exchange argue that the terms of offsetting in these alternative forums are too generous to commercial interests, and this leads to underinvestment at all levels of the mitigation hierarchy. 
Norgaard, R. B. (1994). Development betrayed: The end of progress and a coevolutionary revisioning of the future. London and New York: Routledge.

Piketty, T. (2013). Capital in the twenty-first century. Boston: Harvard University Press.

Rockström, J., Steffen, W., Noone, K., Persson, A., Chapin, F. S., Lambin, E. F., ... Foley, J. A. (2009). A safe operating space for humanity. Nature, $461,472-475$.

Schroeder, M. A., Aldridge, C. L., Apa, A. D., Bohne, J. R., Braun, C. E., Bunnell, S. D., ... Hilliard, M. A. (2004). Distribution of sage-grouse in North America. The Condor, 106(2), 363-376.

Swyngedouw, E. (2009). The antinomies of the postpolitical: In search of a democratic politics of environmental protection. International Journal of Urban and Regional Research, 33 (3): 601-620(609).

Toombs, T. P., Sokulsky, J., \& Wolfe, D. W. (2018). Habitat exchanges: A case study of biodiversity offset design in the U.S. (In preparation).

USFWS. (2010). Endangered and threatened wildlife and plants; 12-month findings for petitions to list the greater sage-grouse (Centrocercus urophasianus). Washington, DC.

Walker, S., Brower, A., Stephens, R., \& Lee, W. (2009). Why bartering biodiversity fails. Conservation Letters, 2, 149-157.

Wolf, S., \& Bonanno, A. (Eds.). (2014). The Neoliberal regime in agri-food: Crisis, resilience and restructuring. London: Routledge/Earthscan.

Wolf, S. A., \& Primmer, E. (2006). Between incentives and action: A pilot study of biodiversity conservation competencies for multifunctional forest management in Finland. Society and Natural Resources, 19(9), 845-861. 
Open Access This chapter is licensed under the terms of the Creative Commons Attribution 4.0 International License (http://creativecommons.org/licenses/ by $/ 4.0 /$ ), which permits use, sharing, adaptation, distribution and reproduction in any medium or format, as long as you give appropriate credit to the original author(s) and the source, provide a link to the Creative Commons licence and indicate if changes were made.

The images or other third party material in this chapter are included in the chapter's Creative Commons licence, unless indicated otherwise in a credit line to the material. If material is not included in the chapter's Creative Commons licence and your intended use is not permitted by statutory regulation or exceeds the permitted use, you will need to obtain permission directly from the copyright holder.

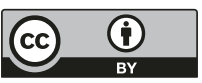

